COMPUTATIONAL SCIENCE AND TECHNIQUES

Volume 8, 2021, 616-624

(C) Klaipeda University, 2021
Publisher: Klaipèda University http://journals.ku.lt/index.php/CST

Online ISSN: 2029-9966

DOI: $10.15181 /$ csat.v8i0.2186

\title{
ADAPTIVE USER INTERFACES AND THE USE OF INFERENCE METHODS
}

\author{
Rachelle Barrette, Ratvinder Grewal \\ Laurentian University \\ Department of Mathematics and Computer Science \\ Sudbury, Ontario \\ rbarrette1@laurentian.cargrewal@laurentian.ca
}

\begin{abstract}
Bayesian Networks can be used to model a user's behaviour using Bayesian Inference. There is not much research on the use of Frequentist Inference to accomplish this same task. This paper aims to analyze and describe the differences between inference methods: Bayesian and Frequentist. A simulation was conducted using Conditional Probabilities that were drawn from the Drupal Usability Study that was conducted in 2012 to apply to both inference methods, Bayesian and Frequentist. Results from this simulation showed that for most probabilities, Bayesian and Frequentist values are reasonably close. Although more frequentist values were equal to $50 \%$ than Bayesian values. With this, it was deduced that for Adaptive User Interfaces, Bayesian Inference is a superior method to use.

Keywords: Adaptive User Interfaces, Bayesian, Frequentist, Inference
\end{abstract}

\section{Introduction}

Software programs are becoming packed with a plethora of features, and it is not feasible for everyday users to fully understand every software program they use in a given day. That is where an Adaptive User Interface comes in; in short, an Adaptive User Interface is an interface that adapts itself, changes itself, according to some criteria (Husain, 2017). The goal of such an interface is to move certain functions or change widgets to accommodate the user. For example, a possible change could be a program's theme from the default to dark for a user that usually changes their theme to dark in other software. For a user that commonly uses an array of commands in a given software program, all toolbars could disappear from the screen, and one toolbar remains to contain the most used commands. This type of adaptation will satisfy the user and make the users' work more efficient since there could be less time spent to find this function or setting. Although, what if the user needs one of the toolbars, but now it is gone? How will that affect the user's mental model (Hui, 2006)? A solution is that a second toolbar could appear with "Features you may like" that could hold functions that are similar to the most frequently used, but what if it still does not include the functions that are needed? Is there a way that these toolbars' choices could be made more accurately without running into the same issue of screen clutter all over again? As can be seen, there is a volume of unanswered questions concerning Adaptive User Interfaces.

To help answer these questions, Bayesian Inference has been suggested to be used by (Hui, 2011) to help deduce at what point a change could be made. For such a method to be used, prior probabilities are necessary to establish a foundation for the Bayesian Inference method to work from. Furthermore, a decision engine, such as a Decision-Theoretic Model, 
is needed to engage as the middleman between the probabilities, the decisions and the implementation (Hui, 2011). Comparatively to Bayesian Inference, the Frequentist Inference (Efron, 2005) method could also be used but has not been suggested for this task yet.

\section{Background}

\section{Adaptive User Interfaces}

An adaptive user interface (AUI) is an interface that changes its' form based on some preset parameters (Husain, 2017). Modifications made to an interface could be of part of a screen, such as a toolbar that changes, or it can be the entirety of an interface. The engine that would power such an interface would be an inference engine. This engine conducts the inference method of choice. Additional parameters can be specified to guide the inference engine such as user preferences, system restrictions, physical restrictions or any other factors.

An example of a partially adaptive user interface is the "apps" page for the Google Pixel 2 on Android 9 in Figure 1. There are two adaptive sections of the interface. The first is the

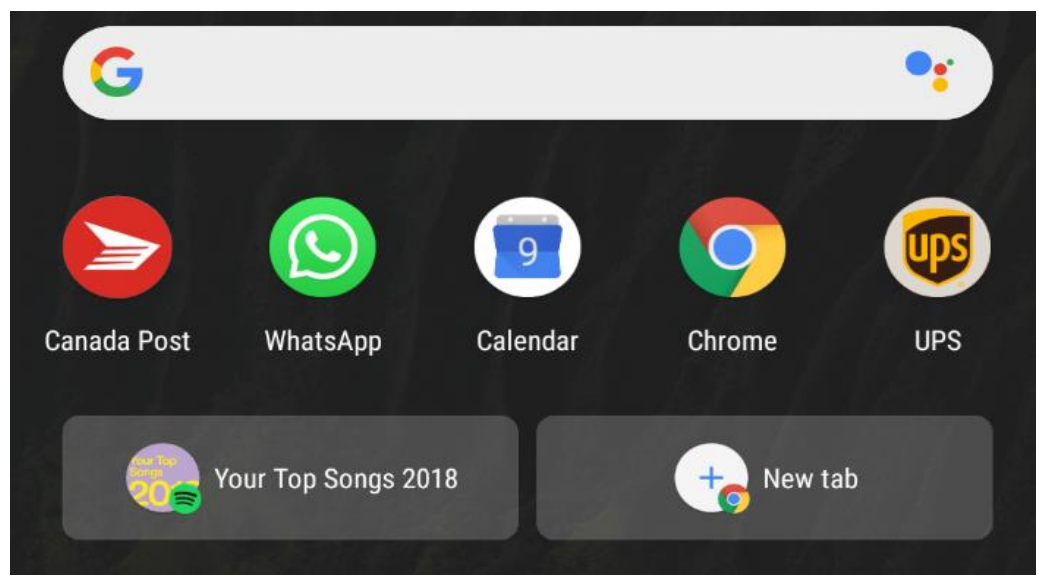
upper section of 5 icons; these icons will change depending on what apps are most recently and frequently used. The second is the set of two actions; these are the last used actions in select apps.

Figure 1. "Apps" page for the Google Pixel 2.

The theoretical principle of an Adaptive User Interface could be mistaken to be flawless, an interface that changes to accommodate the user and the features that they are using most frequently. Users may use a given piece of software differently than the next person. How can an adaptive user interface recognize this and account for this to better accommodate every individual user? Information regarding the user's behaviour would need to be collected regularly. We could then infer a goal from the information collected. The appropriate changes to the user interface are then made based on the inferences. How can the 'appropriate' change be inferred? With this, what would happen to a user's mental model if a change is inappropriate? Will it frustrate the user more? However, it is possible that while the user is taking in new information, during the adaptive process, confusion or frustration occurs if the user has not quite grasped a particular function or its' placement, and the Adaptive User Interface is then changing it while the user is still trying to learn it. Implicit adaptations can be used in this scenario to help users acquaint themselves with adaptive features. (Hui, 2006) stated that some users might find them distracting or unnecessary, furtherly stressing the importance of finding a perfect middle in disruption and awareness with an adaptive system. 


\section{Statistical Inference}

Statistical Inference is a branch of statistics where characteristics of variables are deduced based on the outcomes of a hypothesis test. This type of reasoning has been found useful in many branches of sciences such as Social Sciences, Physics, Biology and even Computer Science. There are two broad schools of Inference: Bayesian Inference and Frequentist Inference. Bayesian Inference carries its' name after Thomas Bayes. Bayes first suggested Bayes' Theorem, also known as Bayes' Rule, in 1763 (Bayes). From there, many other authors have moulded Bayesian Statistics around this Theorem to what it is today. Bayesian Inference uses prior knowledge to shape an inference. Frequentist Inference was created by several researchers' who published papers explaining the Frequentist view roughly around the same time; these statisticians are R. A. Fisher, J, Neyman and E. S. Pearson. (Lehmann, 1993) Parts of each of their methods were accepted and moulded to what Frequentist Inference is today. Frequentist Inference considers the probability of a given event as the frequency of that event happening.

\section{Bayesian Inference}

Bayesian Inference can be presented clearly as a Bayesian Network. A Bayesian Network is a model to present the probabilistic and statistical dependencies between variables, also known as nodes. Child nodes have a probabilistic and statistical dependency on their parent nodes; this means that the probability of the child node is affected by the outcome of the parent node. (Pearl, 2011) Conditional Probability Tables typically accompany each node in a Bayesian Network. These tables contain the corresponding probabilities to the node. Bayes' Theorem uses prior knowledge to update the probability of the posterior; theorem is as follows: (Efron 2013, Triola 2018)

$$
P(H \mid D)=\frac{P(D \mid H) P(H)}{P(D)}=\frac{P(D \mid H) P(H)}{\sum P(D \mid H) P(H)}=\frac{P(D \mid H) P(H)}{P(D \mid H) P(H)+P(D \mid \bar{H}) P(\bar{H})}
$$

$\mathrm{P}(\mathrm{H} \mid \mathrm{D})$ is referred to as the posterior and is also expressed literally as "the probability of the hypothesis $(\mathrm{H})$ given some data (D)" (Olshausen, 2004). The posterior is continually updated with what is learned about the hypothesis while considering new information and the prior. $\mathrm{P}(\mathrm{H})$ is referred to as the prior; this variable englobes any pre-existing knowledge before the data is considered (Olshausen, 2004). If the prior does not exist, it must be specified to conduct Inference (Olshausen, 2004). $\mathrm{P}(\mathrm{D} \mid \mathrm{H})$ is referred to as the likelihood of an event (Olshausen, 2004). $\mathrm{P}(\mathrm{D})$ can also be written as the summation of every $\mathrm{P}(\mathrm{D} \mid \mathrm{H})$ and $\mathrm{P}(\mathrm{H})$, considering the null and alternative hypothesis (Triola, 2018). In the case that there are multiple states, we must create multiple alternative hypotheses to consider all these states. In general, the Bayes' Theorem can be explained as: 'The probability of the hypothesis given some data is equal to the probability of some data given the hypothesis times the prior knowledge divided by the probability of all of the data' (Bayes, 1763).

\section{Frequentist Inference}

Frequentist statisticians interpret probabilities as facts, not as a given belief of a hypothesis. For example, if we were to ask a frequentist what the probability that a coin toss will land on heads is, they would respond with $1 / 2$ since there is an equal probability of a coin landing on 
heads or tails. The probabilities of given events can be found in the conditional probability tables. The likelihood function states that the likelihood of a given hypothesis given some data is equal to the probability of some data given a hypothesis (Orloff, 2014):

$$
\mathrm{L}(\mathrm{H} \mid \mathrm{D})=\mathrm{P}(\mathrm{D} \mid \mathrm{H})
$$

Both methods foster different answers to the inference problem; therefore, which method is best to use? Controversies (that will not be covered in this paper) surround this topic as to which method is statistically sound and scientifically accurate.

\section{Simulation}

In 2012, a usability test was conducted by Becky Gessler at Google, and sponsored by Google, with eight Google employees from various departments (Drupal, 2012). The goal of this study was to understand how new users manage to learn Drupal upon their first try to help reduce the learning curve for new users (Drupal, 2012). The study was conducted over two days (February $1^{\text {st }}$ and $3^{\text {rd }} 2012$ ); on each day, four participants completed the usability test, the tests from each day varied slightly to discover different results (Drupal, 2012). Information about frequently used technologies, experience building websites and experience with CMS's and lastly, experience and knowledge with Drupal were gathered to create User Profiles (Drupal, 2012). Frequently Used Technologies included Linux, Mac, Windows, Google Apps, Photoshop, Microsoft Office Apps, browsers and text editors; therefore, most users are tech-savvy (Drupal, 2012). Previous experience building websites ranged from no experience to HTML, CSS, JavaScript and DreamWeaver (Drupal, 2012). Lastly, most participants did not know what Drupal was. For those who did, they understood that Drupal is a CMS, like WordPress, but had no experience with it (Drupal, 2012). With that, most users went into this study with little to no knowledge of Drupal and some technology skills based on their frequently used technologies. Video and audio were recorded during each participants' session. Throughout the study, participants are asked to think aloud ( speak aloud any thoughts that they had, what they are doing or anything else that came to their mind ). User feedback was summarized and grouped with other similar responses from other users. (Drupal, 2012) to better understand where the shortcomings of Drupal are. After reviewing the findings, we created the following Bayesian Network and Conditional Probabilities (Figure 2):

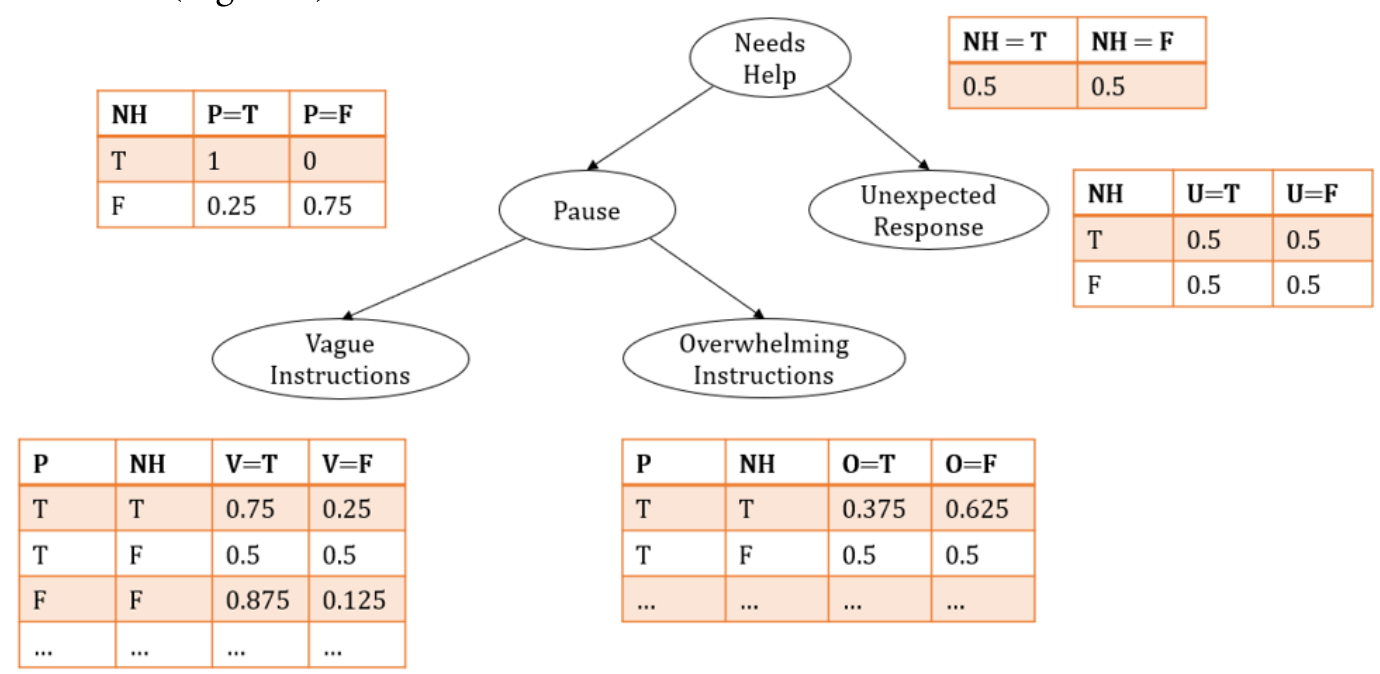

Figure 2. Bayesian Network and Conditional Probabilities. 
In our Bayesian Network, there are five nodes: Needs Help (NH), Pause (P), Unexpected Response (U), Vague Instructions (V) and Overwhelming Instructions (O). Firstly, overwhelming instructions refer to a finding where the user was confused or frustrated by a menu that contained too many options and was unclear as to the different available options. Secondly, Vague Instructions refers to a finding where the user was confused or frustrated with the instruction provided to them, such as a button choice, a field entry and they are unsure of what to do. Thirdly, Pause refers to a finding where because the user encountered an Overwhelming or Vague Instruction, they needed to pause to speak aloud and think through their next step. Unexpected Response refers to a finding where a user thought something different was going to happen upon an action. Lastly, Needs help refers to a finding where the user could either no longer move forward without further help or had to assume a choice based on their mental model and presumptions. To conduct Bayesian Inference, priors need to be specified if they do not exist (Olshausen, 2004). The priors for Unexpected Response, Vague Instructions and Overwhelming Instructions when true is 0.6. The priors for Unexpected Response, Vague Instructions and Overwhelming Instructions when false is 0.4 . These values are chosen since all of the participants have not used Drupal before; they are slightly more susceptible to needing help or pausing if vague instructions, overwhelming instructions or an unexpected response is encountered. The priors for Pause when true is 0.5 . The priors for Pause when false is 0.5 . These values are chosen since we cannot know a participant's pausing behaviour unless the participants are asked directly. Therefore, a prior of 50/50 will not change the outcome of the probability. Table 1 contains a listing of various hypotheses in sets of null and alternative hypotheses. Table 2 contains the probability statements and related value of results for each hypothesis sets.

All of the hypotheses are created in the same format; "A user needs help (or not) and has paused if something has happened.". This "something" can be any of the child nodes of Needs Help(NH); therefore, Pause $(\mathrm{P})$, Overwhelming Instructions $(\mathrm{O})$, Vague Instructions $(\mathrm{V})$ and Unexpected Response $(\mathrm{U})$. These hypotheses are of interest because they can be used to compute the probability that a user needs help given that some event has occurred. These hypotheses help determine if an Adaptive User Interface should make a change if we know in advance that a particular menu overwhelms users or an explanation is vague and causes confusion. Table 1 contains the chosen Hypotheses Statement. Table 2 contains the corresponding evaluations of both inference methods for each hypothesis statement.

\section{Discussion}

The hypothesis set 1 has the intention of finding the probability of the situation where a user needs help and have paused if they have, or have not, encountered vague information. The Bayesian Evaluation estimates an $82 \%$ probability (from Row 1, Table 2) if the user has encountered vague information where the Frequentist Evaluation estimates an $75 \%$ probability (from Row 1, Table 2). The Frequentist value represents a weaker estimation versus the Bayesian value. The Bayesian Evaluation estimates an $18 \%$ probability (from Row 2, Table 2) if the user has not encountered vague information, and Frequentist Evaluation estimates an $25 \%$ probability (from Row 1 , Table 2 ). Both values in these scenarios are close and, therefore, would not make a difference. 
Table 1. Hypotheses Statements

\begin{tabular}{|l|l|}
\hline Set \# & Hypothesis Statement \\
\hline \multirow{2}{*}{1} & A user needs help and has paused if they have encountered vague information. \\
\cline { 2 - 3 } & A user needs help and has paused even if they have not encountered vague information. \\
\hline \multirow{2}{*}{3} & A user does not need help and has paused if they have encountered vague information. \\
\cline { 2 - 3 } & A user does not need help and has paused even if they have not encountered vague information. \\
\cline { 2 - 3 } & A user needs help and has paused if they have encountered overwhelming information. \\
\hline \multirow{2}{*}{5} & A user does not need help and has paused if they have encountered vague information. \\
\cline { 2 - 3 } 5 & A user does not need help and has paused even if they have not encountered vague information. \\
\cline { 2 - 3 } & A user needs help if they have encountered an unexpected response. \\
\hline \multirow{2}{*}{6} & A user needs help even if they have not encountered an unexpected response. \\
\cline { 2 - 3 } & A user needs help if they have paused. \\
\hline
\end{tabular}

The hypothesis set 3 has the intention of finding the probability of the situation where a user needs help and have paused if they have, or have not, encountered overwhelming information. The Bayesian Evaluation estimates an $47.4 \%$ probability (from Row 5, Table 2) when the user did encounter overwhelming instructions where the Frequentist Evaluation estimates an $37.5 \%$ probability (from Row 5, Table 2). When the user did not encounter overwhelming information, Bayesian Evaluation estimates an $52.6 \%$ probability (from Row 6, Table 2) and Frequentist Evaluation estimates an $62.5 \%$ probability (from Row 6, Table 2 ). The Bayesian values are very close to $50 \%$, and therefore, it is difficult to assert whether the user will need help and have paused with such a value.

The hypothesis set 5 has the intention of finding the probability of the situation where a user needs help if they have, or have not, encountered an unexpected response. The Bayesian Evaluation estimates an 60\% probability (from Row 9, Table 2) when the user did encounter an unexpected response where the Frequentist Evaluation estimates an $50 \%$ probability (from Row 9, Table 2). When the user did not encounter an unexpected response, Bayesian Evaluation estimates an $40 \%$ probability (from Row 10, Table 2) and Frequentist Evaluation estimates an 50\% probability (from Row 10, Table 2). In both cases, the Frequentist value returns $50 \%$, which is no better than a coin toss; at least the Bayesian value learns towards an answer.

Most values were close and would not make a difference in the decision process of making changes. Although, in some cases, the probabilities deduced were $50 \%$ for Frequentist, where the Bayesian method returned a value varying from this in these scenarios. The priors can guide the Bayesian probabilities to a final answer. In these cases, the preferred methodology is the Bayesian because it leans more towards an answer versus a 50/50 chance. It is not an evident answer as to which inference method is best to use in any given scenario. The best answer is as Efron stated in his paper in 2005 that:

"The Bayesian-frequentist debate reflects two different attitudes about the process of doing science, both quite legitimate. Bayesian statistics is well suited to individual researchers, or a research group, trying to use all the information at its disposal to make the quickest possible progress. In pursuing 
Table 2. Hypothesis Evaluation

\begin{tabular}{|c|c|c|c|}
\hline Set \# & Probability Statement & Bayesian & Frequentist \\
\hline \multirow[t]{2}{*}{1} & $\mathrm{P}(\mathrm{V}=\mathrm{T} \mid \mathrm{NH}=\mathrm{T}, \mathrm{P}=\mathrm{T})$ & $\begin{aligned}= & \frac{\mathrm{P}(\mathrm{NH}=\mathrm{T}, \mathrm{P}=\mathrm{T} \mid \mathrm{V}=\mathrm{T}) \mathrm{P}(\mathrm{V}=\mathrm{T})}{\mathrm{P}(\mathrm{NH}=\mathrm{T}, \mathrm{P}=\mathrm{T} \mid \mathrm{V}=\mathrm{T}) \mathrm{P}(\mathrm{V}=\mathrm{T})+} \\
& \mathrm{P}(\mathrm{NH}=\mathrm{T}, \mathrm{P}=\mathrm{T} \mid \mathrm{V}=\mathrm{F}) \mathrm{P}(\mathrm{V}=\mathrm{F}) \\
= & \frac{(0.75 \times 0.6)}{(0.75 \times 0.6+0.25 \times 0.4)} \\
= & 0.82\end{aligned}$ & 0.75 \\
\hline & $\mathrm{P}(\mathrm{V}=\mathrm{F} \mid \mathrm{NH}=\mathrm{T}, \mathrm{P}=\mathrm{T})$ & $\begin{aligned}= & \frac{\mathrm{P}(\mathrm{NH}=\mathrm{T}, \mathrm{P}=\mathrm{T} \mid \mathrm{V}=\mathrm{F}) \mathrm{P}(\mathrm{V}=\mathrm{F})}{\mathrm{P}(\mathrm{NH}=\mathrm{T}, \mathrm{P}=\mathrm{T} \mid \mathrm{V}=\mathrm{T}) \mathrm{P}(\mathrm{V}=\mathrm{T})+} \\
& \mathrm{P}(\mathrm{NH}=\mathrm{T}, \mathrm{P}=\mathrm{T} \mid \mathrm{V}=\mathrm{F}) \mathrm{P}(\mathrm{V}=\mathrm{F}) \\
= & \frac{(0.25 \times 0.4)}{(0.75 \times 0.6+0.25 \times 0.4)} \\
= & 0.18\end{aligned}$ & 0.25 \\
\hline \multirow[t]{2}{*}{2} & $\mathrm{P}(\mathrm{V}=\mathrm{T} \mid \mathrm{NH}=\mathrm{F}, \mathrm{P}=\mathrm{T})$ & $\begin{array}{l}=\frac{(0.5 \times 0.6)}{(0.5 \times 0.6+0.5 \times 0.4)} \\
=0.6\end{array}$ & 0.75 \\
\hline & $\mathrm{P}(\mathrm{V}=\mathrm{F} \mid \mathrm{NH}=\mathrm{F}, \mathrm{P}=\mathrm{T})$ & $\begin{array}{l}=\frac{(0.5 \times 0.4)}{(0.5 \times 0.6+0.5 \times 0.4)} \\
=0.4\end{array}$ & 0.25 \\
\hline \multirow[t]{2}{*}{3} & $\mathrm{P}(\mathrm{O}=\mathrm{T} \mid \mathrm{NH}=\mathrm{T}, \mathrm{P}=\mathrm{T})$ & $\begin{array}{l}=\frac{(0.375 \times 0.6)}{(0.375 \times 0.6+0.625 \times 0.4)} \\
=0.474\end{array}$ & 0.375 \\
\hline & $\mathrm{P}(\mathrm{O}=\mathrm{F} \mid \mathrm{NH}=\mathrm{T}, \mathrm{P}=\mathrm{T})$ & $\begin{array}{l}=\frac{(0.625 \times 0.4)}{(0.375 \times 0.6+0.625 \times 0.4)} \\
=0.526\end{array}$ & 0.625 \\
\hline \multirow[t]{2}{*}{4} & $\mathrm{P}(\mathrm{O}=\mathrm{T} \mid \mathrm{NH}=\mathrm{F}, \mathrm{P}=\mathrm{T})$ & $\begin{array}{l}=\frac{(0.5 \times 0.6)}{(0.5 \times 0.6+0.5 \times 0.4)} \\
=0.6\end{array}$ & 0.75 \\
\hline & $\mathrm{P}(\mathrm{O}=\mathrm{F} \mid \mathrm{NH}=\mathrm{F}, \mathrm{P}=\mathrm{T})$ & $\begin{array}{l}=\frac{(0.5 \times 0.4)}{(0.5 \times 0.6+0.5 \times 0.4)} \\
=0.4\end{array}$ & 0.25 \\
\hline \multirow[t]{2}{*}{5} & $\mathrm{P}(\mathrm{UR}=\mathrm{T} \mid \mathrm{NH}=\mathrm{T})$ & $\begin{array}{l}=\frac{(0.5 \times 0.6)}{(0.5 \times 0.6+0.5 \times 0.4)} \\
=0.6\end{array}$ & 0.5 \\
\hline & $\mathrm{P}(\mathrm{UR}=\mathrm{F} \mid \mathrm{NH}=\mathrm{T})$ & $\begin{array}{l}=\frac{(0.5 \times 0.4)}{(0.5 \times 0.6+0.5 \times 0.4)} \\
=0.4\end{array}$ & 0.5 \\
\hline \multirow[t]{2}{*}{6} & $\mathrm{P}(\mathrm{P}=\mathrm{T} \mid \mathrm{NH}=\mathrm{T})$ & $\begin{array}{l}=\frac{(1 \times 0.5)}{(1 \times 0.5+0 \times 0.5)} \\
=1\end{array}$ & 1 \\
\hline & $\mathrm{P}(\mathrm{P}=\mathrm{F} \mid \mathrm{NH}=\mathrm{T})$ & $\begin{array}{l}=\frac{(0 \times 0.5)}{(1 \times 0.5+0 \times 0.5)} \\
=0\end{array}$ & 0 \\
\hline
\end{tabular}


progress, Bayesians tend to be aggressive and optimistic about their modelling assumptions. Frequentist statisticians are more cautious and defensive. One definition says that a frequentist is a Bayesian trying to do well, or at least not too badly, against any possible prior distribution. The Frequentist aims for universally acceptable conclusions, ones that will stand up to adversarial scrutiny. The FDA, for example, does not care about Pfizer's prior opinion of how well a new drug will work; it wants objective proof. Pfizer, on the other hand, may care very much about its own opinions in planning future drug development" (Efron, 2005).

\section{Conclusion and Future Work}

The simulation deduced that the Bayesian Inference method is a more reliable method to use for Adaptive User Interfaces. Firstly, the Bayesian method considers prior events that have happened in its' calculations. Secondly, the Bayesian method generates, less, values equal to $50 \%$ than the Frequentist Inference method. Lastly, in the case where the Frequentist method returns a value of $50 \%$, the Bayesian method will be better suited for deciding whether a change is warranted or not since its' value differs from $50 \%$, either higher or lower, it will not be left to a 50/50 guess to decide.

Firstly, it would be of interest to reconduct an evaluation of this sort with a more comprehensive dataset where additional hypothesis statements could be tested to generate a more extensive list of results and where a more definitive conclusion could be stated. Secondly, it would also be interesting to learn to what extent an interface can be changed before it interrupts the user's mental model too much. As explained before, we already know that menu items and menus can be swapped, which generally goes unnoticed by users (Hui, 2006). What more can be done than merely swapping menu items? The above question could be answered through future research by experimenting with real participants. Thirdly, various biometrics could be recorded to provide a more thorough evaluation, such as heart rate, eye tracking, brain responses and movement tracking. Lastly, further research could include implementing the Bayesian Inference method with a Decision-Theoretic Model or Fuzzy Inference system to decide under uncertainty. (Hui, 2011)

\section{References}

Bayes, T., 1991. An essay towards solving a problem in the doctrine of chances. 1763. MD computing: computers in medical practice, 8(3), p.157.

Drupal. 2012 Google UX Study 2012 Detailed Results, viewed on January 8th 2021 $<$ https://www.drupal.org/docs/develop/usability-testing/drupal-usability-testresults/google-ux-study-2012-detailed-results>

Efron, B. Bayes' Theorem in the 21st century. Science, 340(6137), 1177-1178. (2013).

Efron, B., 2005. Bayesians, frequentists, and scientists. Journal of the American Statistical Association, 100(469), pp.1-5.

Hui, B. and Boutilier, C., 2006. Modeling the Disruption to the User's Mental Model. In Neural Information Processing Systems (NIPS), Workshop on User Adaptive Systems.

Hui, B., 2011. A methodological framework for decision-theoretic adaptation of software interaction and assistance (Doctoral dissertation). Viewed on January 8th 2021 <https://tspace.library.utoronto.ca/handle/1807/31785> 
Husain, WNLW and Jantan, A.H., 2017. Adaptive User Interface Design: A Case Study of Web Recommendation System. Journal of Telecommunication, Electronic and Computer Engineering (JTEC), 9(3-3), pp.137-140.

Lehmann, E.L., 1993. The Fisher, Neyman-Pearson theories of testing hypotheses: one theory or two?. Journal of the American statistical Association, 88(424), pp.1242-1249.

Olshausen, B.A., 2004. Bayesian probability theory. The Redwood Center for Theoretical Neuroscience, Helen Wills Neuroscience Institute at the University of California at Berkeley, Berkeley, CA.

Orloff, J. and Bloom, J., 2014 Comparison of frequentist and Bayesian inference. MIT OpenCourseWare.Viewed on January 8th 2021 < https://ocw.mit.edu/courses/mathematics/18-05-introduction-to-probability-andstatistics-spring-2014/readings/MIT18_05S14_Reading20.pdf>

Pearl, J., 2011. Bayesian networks.

Triola, M. F. (2018) Elementary Statistics 13th edition. Pearson.

R. Barrette is a Graduate student in the Master of Science in Computational Science program at Laurentian University. Rachelle's research interests include user interfaces, user experience and cognitive load.

R. S. Grewal is an associate professor in the Department of Mathematics and Computer Science at Laurentian University. Ratvinder received his $\mathrm{PhD}$ in 2001 from the University of Wolverhampton. Ratvinder does research in the field of Human-Computer Interaction.

\section{ADAPTYVIOS NAUDOTOJO SĄSAJOS IR IŠVEDIMO METODŲ TAIKYMAS Rachelle Barrette, Ratvinder Grewal Santrauka}

(Hui, 2011) ir kiti pasiūlè modeliuoti naudotojo elgseną taikant Bajeso tinklus. Šiuo požiūriu nèra tiek daug atliktų tyrimų kaip taikant dažninius išvedimo metodus. Šiame straipsnyje analizuojami ir aprašomi Bajeso ir dažninio išvedimo metodų skirtumai. Pristatyti modeliavimo rezultatai paremti „Drupal“ naudojimo tyrimu, atliktu $2012 \mathrm{~m}$. Tyrime gauta sąlyginè tikimybė yra naudojama šiame darbe pristatomo modelio simuliacijoje abiems išvadimo metodams. Rezultatai parodè, kad daugumai tikimybių Bajeso ir dažninès vertès yra gana artimos. Pastebëjome, kad dažninių tikimybių vertės buvo lygios reikšmei $1 / 2$ dažniau nei Bajeso tikimybès igydavo tokią reikšmę. Todèl adaptyvioms naudotojo sąajoms Bajeso išvedimo metodas yra pranašesnis metodas nei dažninis.

Pagrindiniai žodžiai: adaptyvios naudotojo sąsajos, Bajeso (Bajesinis), dažninis, išvedimas 